\title{
FROM QUANTITY TO QUALITY - \\ AN ASPECT OF EDUCATIONAL DEVELOPMENT IN CEYLON
}

Dr. Premadasa Udagama

Permanent Secretary, Ministry of Education, Ceylon

Since the achievement of independence in 1948, school enrolments in Ceylon have doubled and currently stand at over 2.64 million children. This increase has been matched by the construction of some twenty-eight thousand new classrooms as well as by the remodelling and enlargement of the older buildings inherited from the colonial period. Now, in 1971, with universal free primary education and a very substantial proportion of the children of secondary school age receiving education, the Government is able to turn its attention from the problems of quantity to those of quality. This, of course, is not to suggest that the quantitative problems have entirely disappeared - they have not. It is, however, true to say that they have eased sufficiently for greater attention to be paid to matters such as the adjustment of the structure of education, improvement of the curriculum, teacher training and re-training and, last but by no means least, to the improvement of the physical environment for teaching and learning.

The climate of much of Ceylon is both hot and humid. It is, how ever, a comfort able climate due to the cool sea breezes that blow throughout the year. The standard school building has been designed to take advantage of those breezes and comprises an open hall with wide overhanging roof and big openings in the external walls in place of the customary windows. There are usually no brick divisions between one class and the next. This arrangement has many advantages: as numbers have grown, classes have been able to adjust along the length of the hall, unobstructed by dividing partitions; when a teacher is sick, two classes can very easily be joined and managed by one teacher; team-teaching, although not generally practised, is possible; changes in the structure of education and in the curriculum are not inhibited by rooms of the wrong size. Most important of all, perhaps, is the fact that the se buildings are very cheap indeed to construct, costing, at current prices, about US $\$ 30$ per place.

Although the use of the low-cost, open hall type school has enabled Ceylon to house the bulk of its population of school-going age and thus helped to resolve the quantitati ve problem that still besets many other Asian countri es, the open character of the buildings has, in some ways, retarded qualitative development. Because there are no division walls between classes, there are no large chalkboards or pin-up boards, and the teacher has to make do with a small wooden blackboard and easel. There is, moreover, no storage space either for the teacher's materials or for student work. Whilst there appears to be little distraction due to noise between one class and the next, there is certainly some visual distraction as all classes can watch each other.

Thus, in its current efforts to improve the quality of education, the Government decided inter alia to see what could be done to improve the physical envi ronment of the classroom, without, of course, losing the advantages of flexibility inherent in its standard school designs. The first solutions to the problem were developed in the Ministry of Education's Regional School Building Research Institute ${ }^{1}$ and comprised a free-standing double-sided division unit which included storage spaces for both teachers 


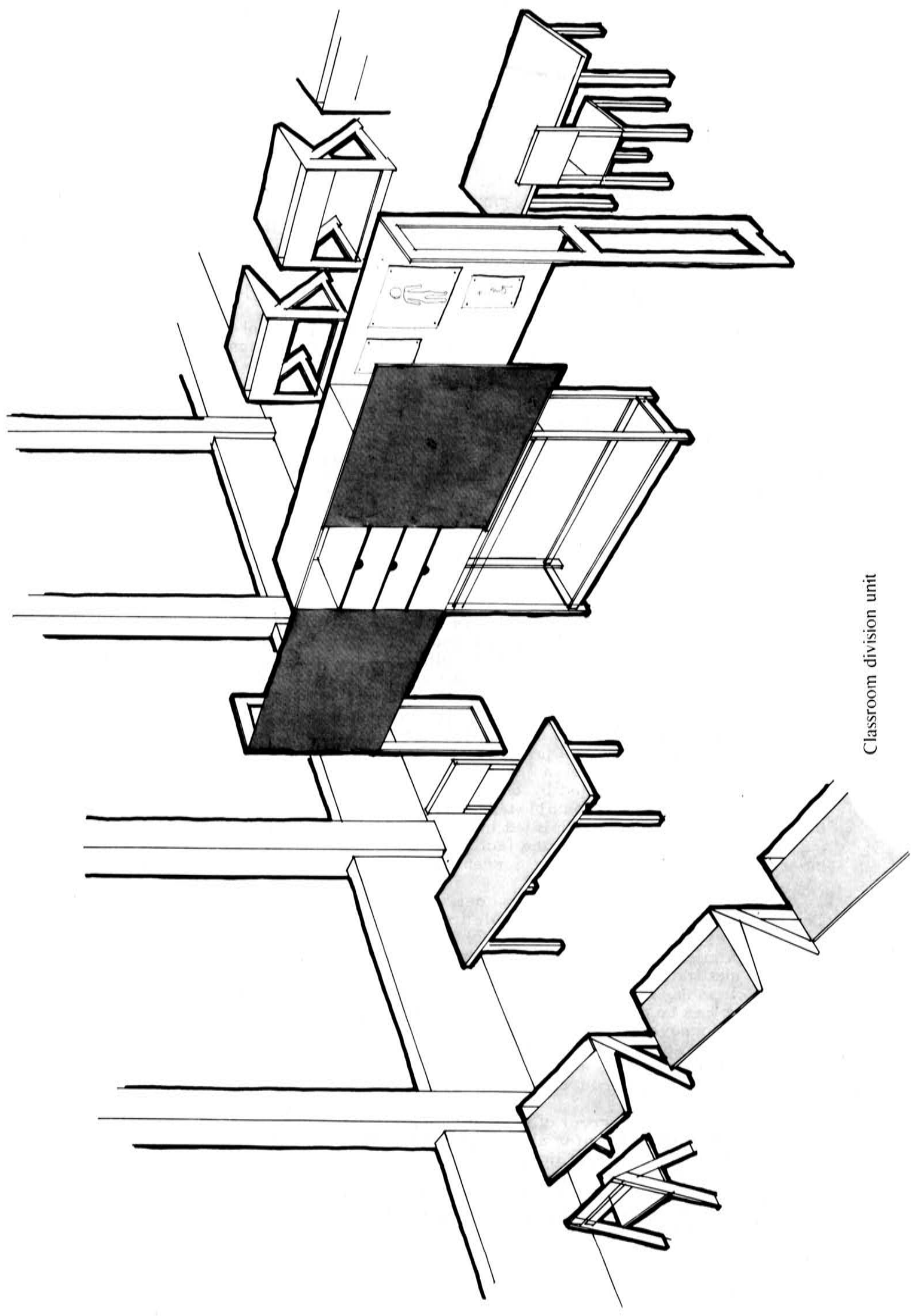


using it, as well as over 2 metres of chalkboard and a metre of softboard for pinning (Figure 1 ). These units, costing about $\$ 83$, together with more functional desks and chairs, specially designed by the Institute in relation to the body sizes of Ceylon's children, have now been installed in one hundred schools.

\section{Movable trolleys}

Improvement of the physical facilities in classrooms is, however, only one aspect of a much wider problem. Facilities for handicrafts teaching and learning and science teaching and learning in the secondary schools need to be improved. Only some 600 schools have laboratories for lower secondary level science and only 160 for science at the upper secondary level. The cost of traditional laboratories has been very high in the past and this is one of the reasons why so few of them have been built. The Institute developed a cheap, prefabricated, demountable science storage unit which could be located in a hall type building and with it, science tables and stools. The storage unit houses movable science trolleys. When a science lesson is to be given, these are wheeled out, complete with water and sink (in local plastic). When the lesson is completed, the trolleys are put away and the teacher gets on with the next lesson which may be geography or history. The same trolleys can be used for handicrafts mat erials also. Thus, through the introduction of this simple, inexpensive unit (costing about US\$330) into 100 standard hall type schools, the Ministry of Education has made science teaching and learning possible in situations where before, because of the high cost of the tradi tionally designed laboratory, it had been impossible (Figure 2).

The most ingenious aspect of this story has, how ever, been left to its end. In June 1971, the Government of Ceylon started to examine both the structure and content of its educational system. At the time of writing, the discussion on the policies to be adopted are continuing and it will obviously be a long while before the changes proposed are fully implemented. It is clear at this stage, however, that far greater attention will be paid in future to job-oriented education at the upper primary and lower secondary levels. At present, not only are the facilities for subjects such as woodwork in the schools very limited, but the nature of the teaching is highly academic in character. Handicrafts, the Ministry of Education decided, should not be confined to the learning of skills but should also lead to the development of desirable attitudes towards the world of work and industry. This, it was reasoned, was more likely to take place if, instead of the small and often useless models made in handicrafts classes, the children worked at exercises which they themselves could plan, construct, utilize and evaluate.

\section{Desks and chairs made in the schools}

It was at this stage of the thinking that the Ministry of Education decided to link the improvements they desired in the quality of the schemes of work for carpentry with the improvements planned in the classrooms, through the introduction of better desks and chairs. A seminar was arranged for all the country's Inspectors of woodwork at which the construction of the very simple desk and chair (Figure 3) designed in the Ministry's Research Institute, was explairied. Sufficient working drawings to distribute to over 500 schools were printed and the Inspect ors returned to their regions to conduct in-service courses for woodwork teachers to 


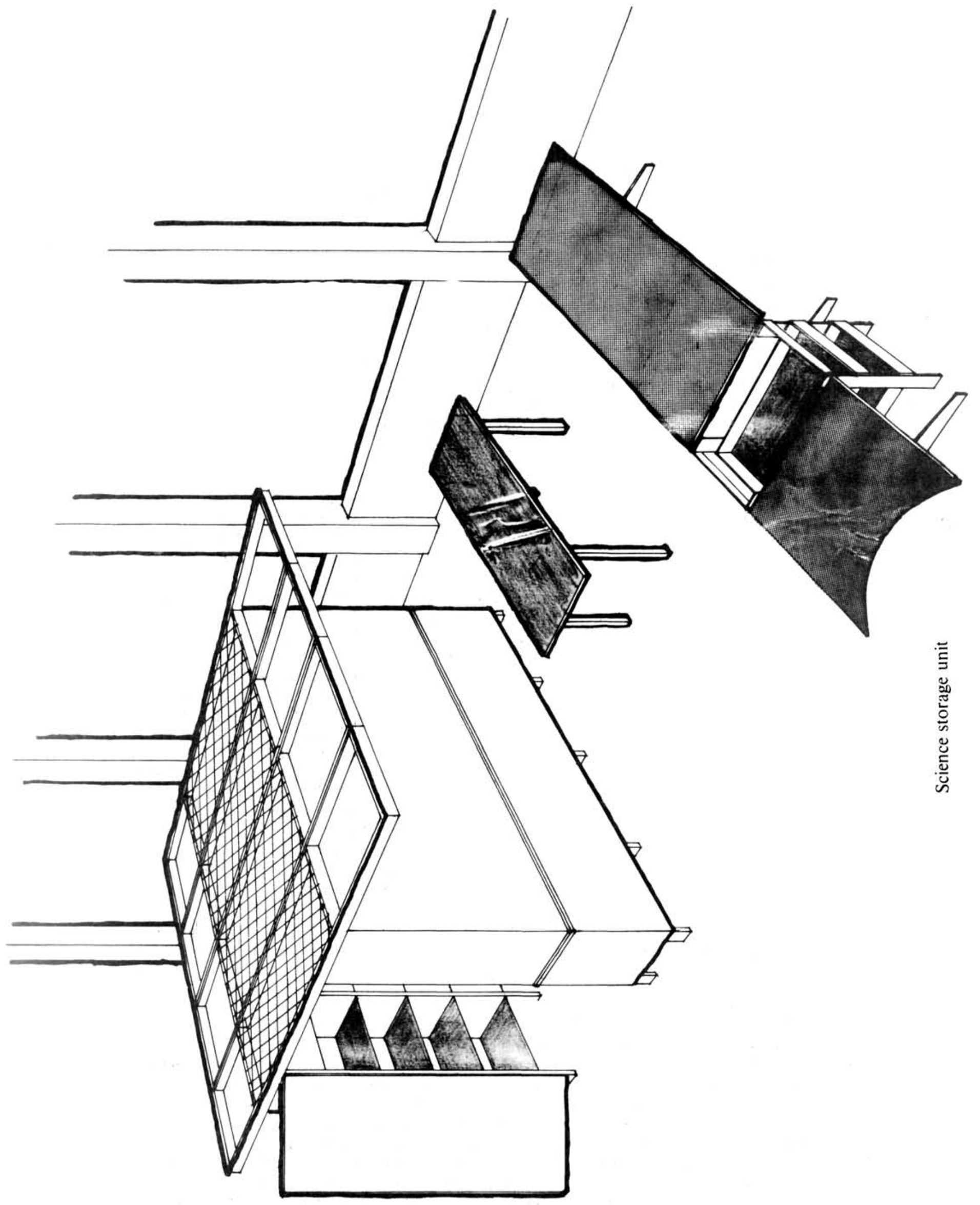




$$
\sqrt{\frac{1}{4}}
$$


introduce the new desk and chair as learning units in the lower secondary school system.

During the next year, some thousands of desks and chairs will be made in Ceylon's schools and this activity will have an impact not only on the quality of teaching and learning in handicrafts, but also on the general quality of the classroom environment in which it takes place.

1. ARISBR - a unit of the Ministry - sponsored by Unesco and having regional functions in respect of educational buildings. 